Силкина Лидия Александровна

студентка

Лукин Роман Сергеевич

старший преподаватель

ФГАОУ ВО «Сибирский федеральный университет»

г. Красноярск, Красноярский край

DOI $10.21661 / r-463710$

\title{
APPLICATION OF SUBMODELING TECHNOLOGY TO SHEET METAL STRUCTURES OF LIFTING EQUIPMENT
}

Аннотация: в статье показаны результаты применения технологии подмоделирования к анализу листовых металлоконструкиий, моделируемых оболочечныли или объемныли элементами. Показаны критерии возникновения сингулярности в модели и способы нахождения действительных напряжений в зоне концентрацуии путем использования в расчете уточненной геометрии.

Ключевые слова: метод конечных элементов, подмоделирование, сварной шов, эквивалентные напряжения, сингулярность.

Abstract: the article shows the results of applying the submodeling technology to the analysis of sheet metal structures, modeled by shell or solid elements. Criteria for the appearance of a singularity in the model and methods for finding the actual stresses in the concentration zone are shown by using the corrected geometry for solution performing.

Keywords: finite element method, submodeling, weld seam, equivalent stresses, singularity.

It is sometimes necessary to create volumetric and complex models in order to find the actual effective stresses of the responsible structures. However, this is not always possible due to the hardware limitations and the time-limited preparation of the model. To find real values of stresses at a specific point of the model it is possible to use the Hot Spot Stress method which is described in the source [1]; however, in addition to the necessity of results post-processing by means of finite element calculations, 
it becomes necessary to make finer the mesh by regulating the size of the element, which should be equal to a half of the thickness of the joined sheets [1, p. 135]. Also in some cases, the plasticity of the material is also taken into account, but this leads to an increase in the convergence time, and as well does not always guarantee the real stress finding. In turn, the technology of submodeling (SM) allows to decompose the task and subtasks, which reduces the load on the hardware. The main target of the SM getting satisfactory results of stresses on a certain area of the model where inaccurate results were obtained on a mesh of insufficient density. So, you can obtain an accurate result on a smaller elements mesh by creating a submodel of the stress concentration region. The main principle is a transfer (an interpolation) of the nodes displacements obtained from the calculation of the full model in the locations of the submodel boundaries at the nodes of the submodel.

The article [3] says that it is possible to find the specified values of stresses in the zone of soldering the flange of the waveguide channel element with the help of this technique, while the ratio of the stress values in the basic and refined model reaches 1.8. Also SM-technology has found its application in analyzing the cylinder head of a highly-compressed diesel engine during temperature analysis [2, p. 47]. The task was modeled by solid (3D) elements. The problems of it are: a long calculation time due to the large number of degrees of freedom and a presence of nonlinear contacts. An application of the SM have allowed to find the stress values in the nozzle zone, while the number of elements along the bridge could be increased from one to four. However, the using of the SM requires additional studies in applying it to sheet structures that are modeled by shell finite elements. The calculation of the traverse (fig. 1) using the solid-solid and solid-shell method have been considered as an example of this technology realization. The stresses and the strains of the traverse (the basic model) are determined from the calculation results. 


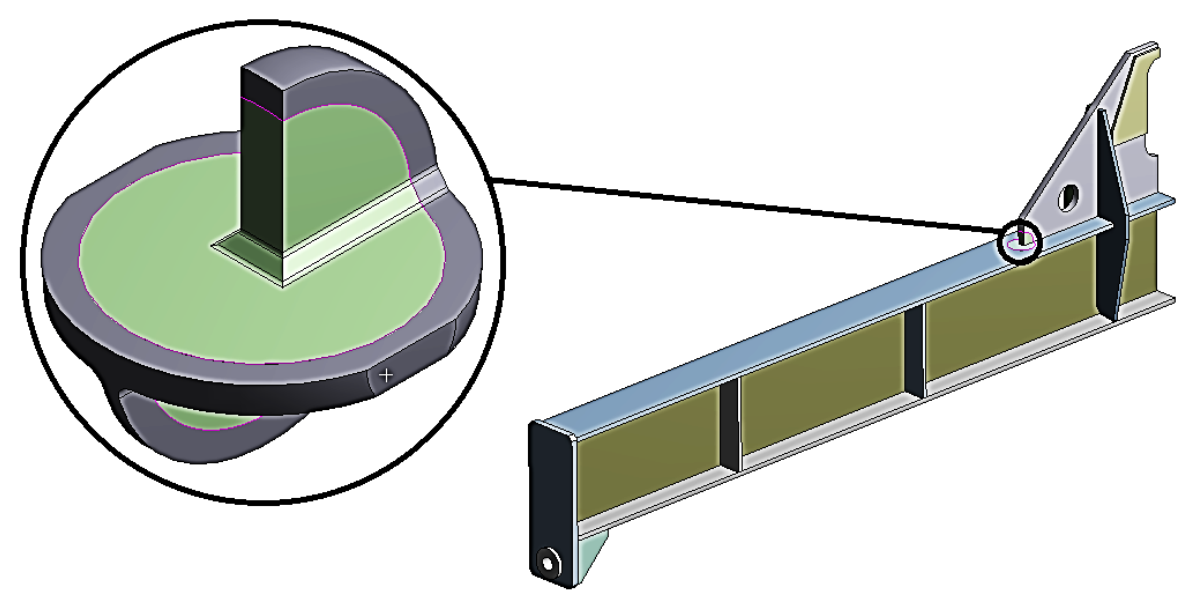

Fig. 1. Importation of displacements to the submodel, thickening of the mesh in the required area

As a truth estimating criterion of values of equivalent stresses have been proposed a criterion of equality of averaged and unaveraged stresses, as well as the absence of stress growth as a result of meshing the mesh in the stress concentration zone.

The equivalent stresses increase as the size of the element decreases. This dependence is reflected in the graph (fig. 2b). The upper line shows the unaveraged values, the lower line shows the averaged values. The ratio of the unaveraged stresses to the average is 2 . At the same time, the stresses significantly exceed the resistance limit [4] for the strength class of a steel 345; however there is a danger of assuming the obtained stress value due to the satisfaction to the strength condition for a large element size (including for the shell model, see fig. 3 b). Similarly, approximating the obtained values by a power function, we obtain that if the element size is set to zero, the stresses tend to infinity. 


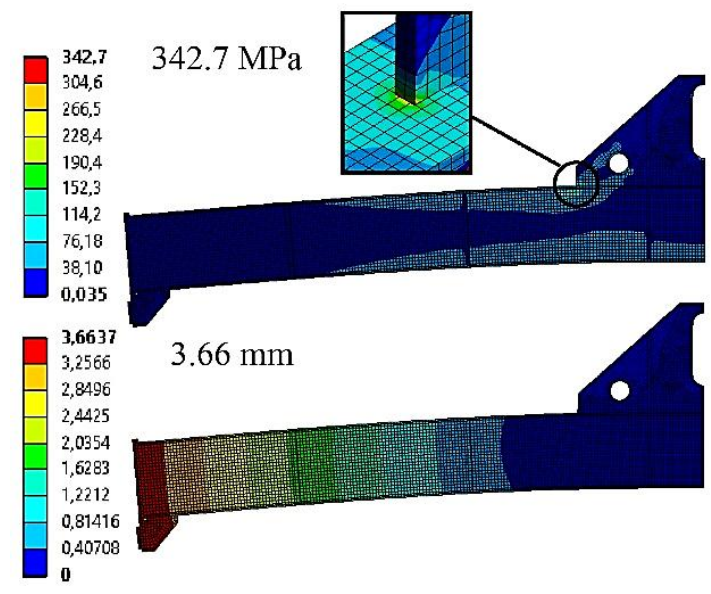

a)

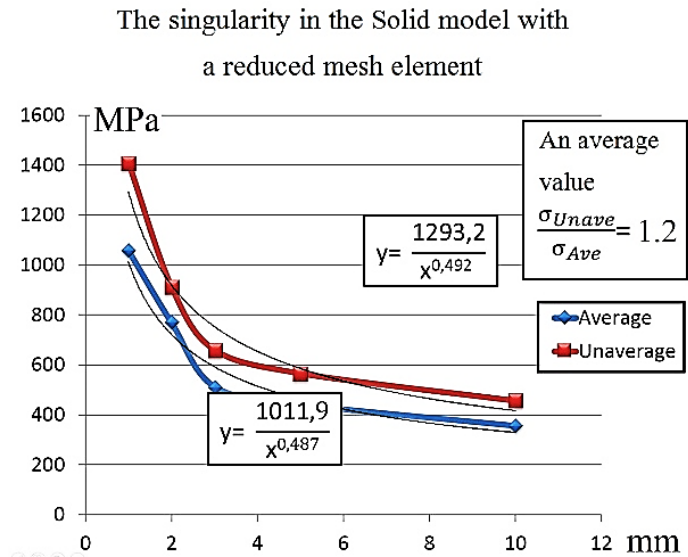

b)

Fig. 2. The calculating results of the volume finite elements model:

$a-$ pictures of stresses and strains; $b$ - graph of stress changes

Submodeling the shells it is necessary to take into account the importing features of the displacements from the basic model to the submodel. Since solid elements have 3 degrees of freedom per node (linear), and for shell ones - six, linear displacements are converted into twisting (angular deformation of the shell).Being calculated the traverse by the shell method, a similar singularity effect and a mismatch between the averaged and non-averaged stresses are observed. That is, the use of shells with a fine mesh in comparison with the solid model does not preclude the possibility of a singularity.

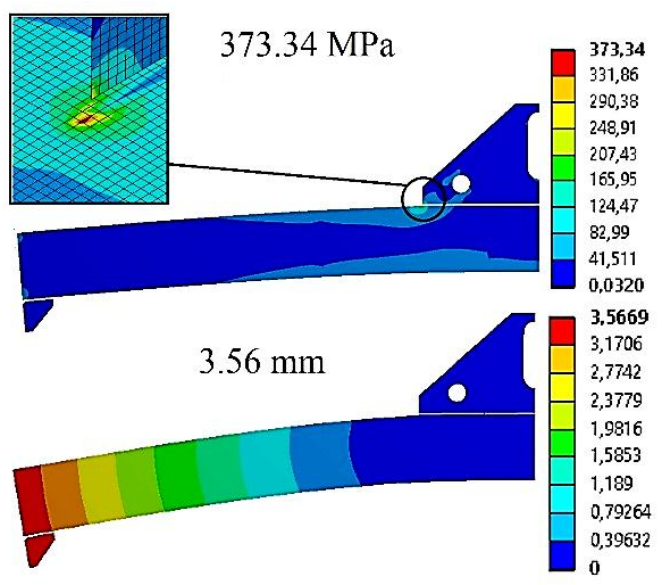

a)
Сингулярность в модели Shell при

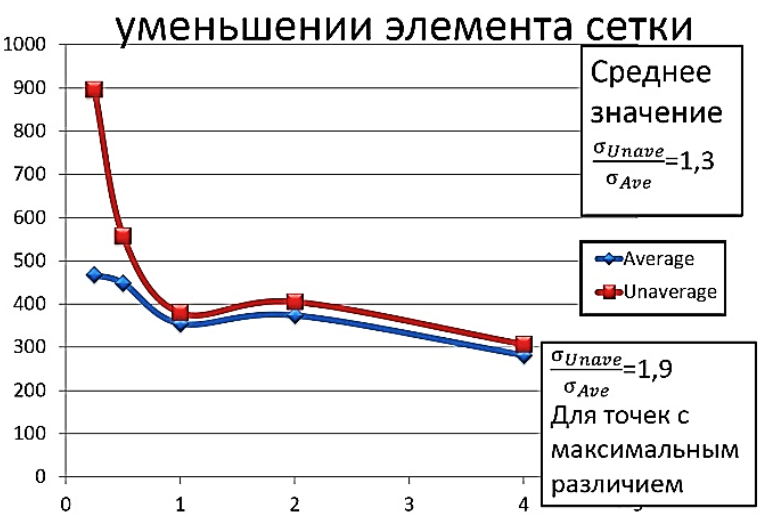

b)

Fig. 3. The calculating results of the shell model: $a-$ pictures of stresses and strains; $b$ - graph of stress changes 
It is necessary to create a thickened mesh in the weld zone for the created submodel. The submodeling calculation results with different element sizes show that the stresses grow up with element size decreasing (fig. 3b). In this case, there is also a singularity.

The solution of this problem is the approximation of the real model geometry: that is, the insertion of the weld geometry and the small sized fillets. Below are the calculation results of the traverse submodeling with the original and modified geometry (figures 4,5$)$.

According to the modeling results the table was compiled (Table 1), from which it can be seen that with a changing of the element size, a considerable increase in stress is observed. However, as can be seen from Fig. 5b, for a submodel with a fillet at an element size $\leq 0.4 \mathrm{~mm}$, the stresses practically do not change.

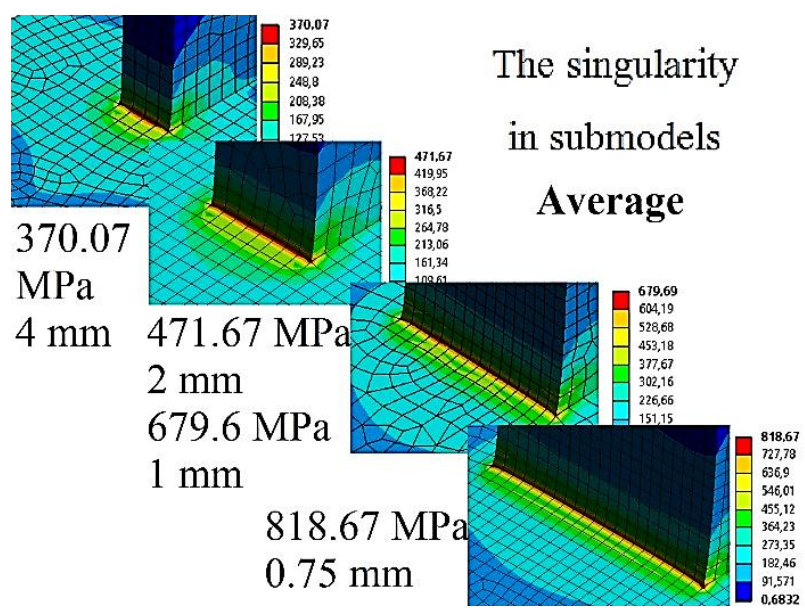

a)

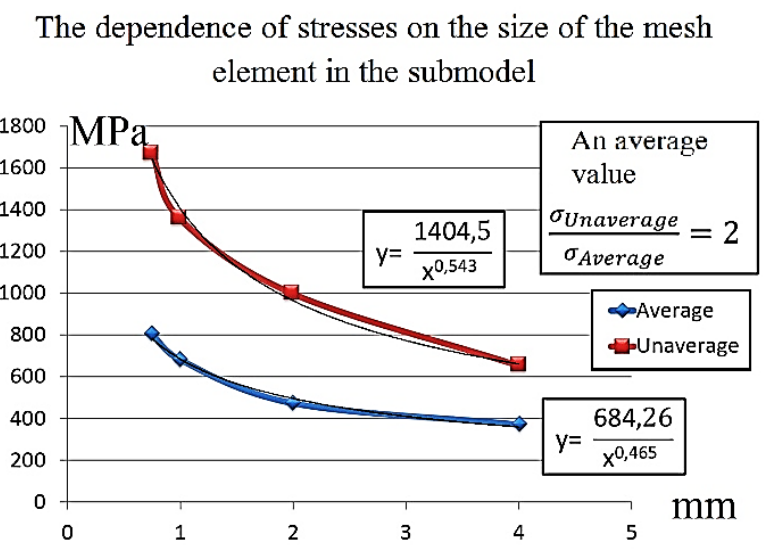

b)

Fig. 4. The results of the submodel calculation are:

$a-$ stress patterns; $b$ - graph of stress changes 


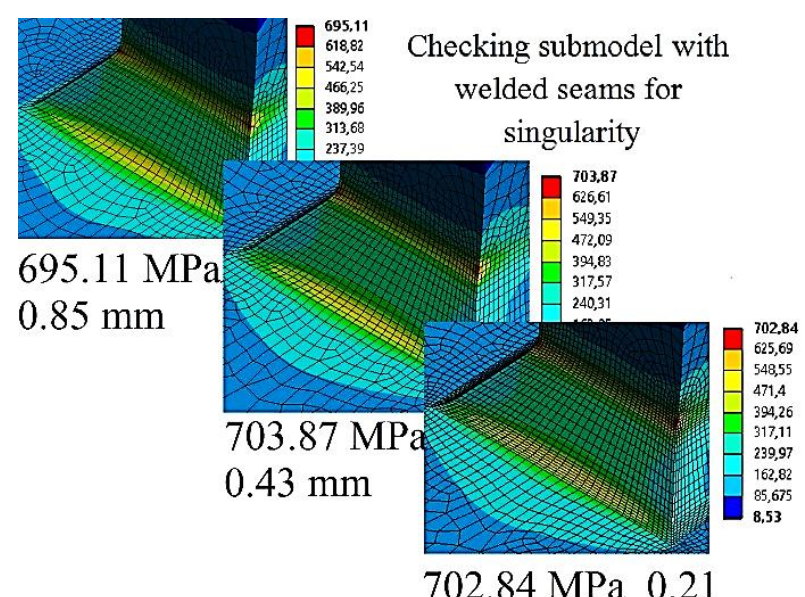

a)

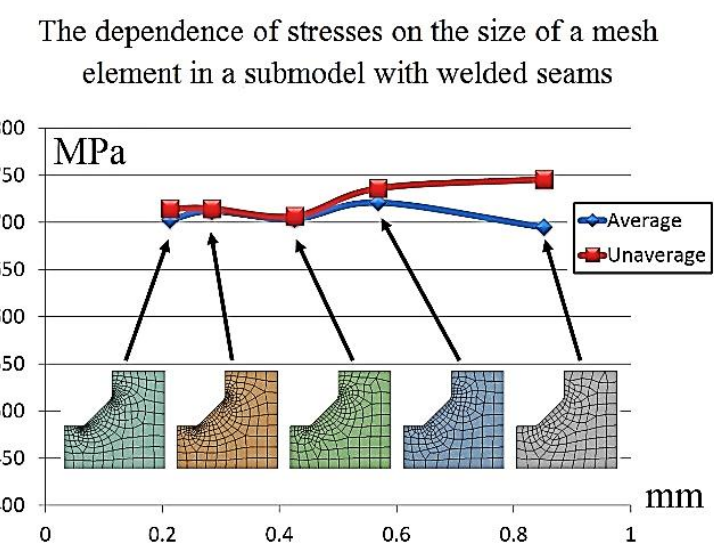

b)

Fig. 5. The calculation results of the submodel with the applied welds:

$a-$ stress patterns; $b$ - graph of stress changes

Table 1

Values of equivalent stresses, $M P a$

\begin{tabular}{|l|c|c|c|c|}
\hline \multirow{2}{*}{} & \multicolumn{2}{|c|}{ Solid-Solid } & \multicolumn{2}{c|}{ Shell-Solid } \\
\cline { 2 - 5 } & Average & Unaverage & Average & Unaverage \\
\hline The model & 342.70 & 403.13 & 281.76 & 305.98 \\
\hline The model with fine mesh & 769.11 & 912.2 & 467.43 & 895.34 \\
\hline The submodel & 695.25 & 706.32 & 733.94 & 745.57 \\
\hline
\end{tabular}

In this article, the applicability of the technology of submodeling to the analysis of complex structures has been examined. The application of this technology meets modern production requirements for the analysis of large models, which include parts that need to be modeled by shells or beams. In this case, the possibility of calculating a simplified basic model with subsequent transfer of displacements to a submodel with a corrected geometry is shown, which makes it possible to find real values of stresses.

\section{References}

1. Bannikov D.O., Guslistaya A.E. Correcting accounting results of tensions using fem by HSS method. Nauka I Progress Transporta. Vestnik Dnepropetrovskogo Natsionalnogo Universiteta Zheleznodorozhnogo. - 2011. - №38. - P. 134-141 (In Russ).

2. Myagkov L.L., Malastovskiy N.S., D'yakova L.N., Blinov A.S. Thermal stress analysis of a high performance diesel engine cylinder head Proceedings of Higher Educational Institutions. Machine Building. - №2 (659). - 2015. - P. 42-52 (In Russ). 
3. Silkina L.A. Technology of submodeling for analyzing spacecraft elements. Reshetnev readings. - 2016. - Vol. 1. - №20. - P. 455-457 (In Russ).

4. SNiP II-23-81 Stal'nyye konstruktsii [Steel structures]. - Moscow, Standartinform Publ, 2011. - 173 p. 